\title{
Diagnostic and Management Strategies in Patients with Persistent Fetal Vasculature: Current Insights
}

This article was published in the following Dove Press journal:

Clinical Ophthalmology

\author{
Supalert Prakhunhungsit $\mathbb{D}^{\prime}$ \\ Audina M Berrocal ${ }^{2}$ \\ 'Department of Ophthalmology, Faculty \\ of Medicine Siriraj Hospital, Mahidol \\ University, Bangkok, Thailand; ${ }^{2}$ Bascom \\ Palmer Eye Institute, Miller School of \\ Medicine, University of Miami, Miami, \\ FL, USA
}

\begin{abstract}
Persistent fetal vasculature (PFV), previously known as persistent hyperplastic primary vitreous, is a developmental malformation of the eyes that is caused by a failure of the hyaloid vasculature to regress in utero. PFV has been reported for decades; however, our understanding of the pathophysiology/pathogenesis of PFV, and the diagnostic and treatment modalities for PFV have evolved over time, and these advancements have improved diagnosis, treatment, and outcomes. However and in spite of these advancements, the heterogeneity of this disease continues to make PFV a diagnostic challenge. Here, we review what is currently known about various important aspects of PFV to update and enhance the knowledge of ophthalmologists who encounter and manage PFV in clinical practice.
\end{abstract}

Keywords: diagnostic and management strategies, persistent fetal vasculature, PFV, current insights

\section{Introduction}

Persistent fetal vasculature (PFV), previously referred to as persistent hyperplastic primary vitreous (PHPV), is a developmental malformation of the eyes that is caused by a failure of the hyaloid vasculature to regress. The vascular remnant connects between the optic nerve head posteriorly to anterior ocular structures, such as the lens and ciliary process, and it manifests variably among patients, including anterior, posterior, and combined types. ${ }^{1,2}$ The heterogeneity of this disease makes diagnosis challenging. Even though PFV has been investigated and described for decades, our understanding of the pathophysiology/pathogenesis of PFV, and the diagnostic and treatment modalities for PFV have evolved over time, and these improvements have enhanced the accuracy of diagnosis, treatments, and patient outcomes. The aim of this review was to present the currently available information and evidence specific to various important aspects of PFV with the intent of bringing ophthalmologists up-to-date relative to the diagnosis and treatment of PFV.

\section{Genetics}

The majority of cases of PFV occur sporadically; however, some other patterns of inheritance have also been reported, such as autosomal recessive form in cases with ATOH7 gene mutation on chromosome 10q21.3. ${ }^{3,4}$ A dominant pattern of inheritance in PFV was also described in an Egyptian family..$^{5} \mathrm{NDP}$ gene and COX15 gene mutations on chromosome 10 were also reported in bilateral PFV cases. ${ }^{6-9}$ Apart from the aforementioned genes, the ZNF408 gene, which was previously found in autosomal recessive retinitis pigmentosa and autosomal dominant familial exudative
Correspondence: Audina M Berrocal Bascom Palmer Eye Institute, Miller School of Medicine, University of Miami, 900 Northwest 17th Street, Floor I, Miami, FL 33।36, USA

Tel +l 305-326-6000

Email aberrocal@med.miami.edu 
vitreoretinopathy (ADFEVR), was also described in PFV cases with microcornea, posterior megalolenticonus, persistent fetal vasculature, and coloboma syndrome (MPPC syndrome).$^{10}$ FZD4 (Frizzled class receptor 4), which is a gene related to familial exudative vitreoretinopathy (FEVR), was also found to be related to some PFV cases. ${ }^{11}$ However, in bilateral cases of PFV with cardiovascular and central nervous system abnormalities, Trisomy 13 (Patau syndrome) should be suspected and ruled out. ${ }^{12}$ Consultation with an ocular geneticist is recommended in cases of bilateral PFV to rule out other ocular or systemic associations, as well as for genetic counselling relative to future offspring in complex patients. ${ }^{9}$

\section{Pathophysiology of PFV}

In an embryo, the formation of vessels starts as early as the third week of gestation. During this period, hyaloid artery systems begin to develop and grow to the anterior part of the eye forming the iridohyaloid or capsulopupillary artery. The anastomosis of vessels at the back of the developing lens, which is called posterior tunica vasculosa lentis, starts and nourishes the lens during this stage of its development. ${ }^{1,2,13}$ In the second trimester of pregnancy, secondary vitreous starts to form in the place of primary vitreous. Then, regression of the hyaloidal artery followed by vasa hyaloidal propria, iridohyaloid, and tunica vasculosa lentis occurs via apoptosis or macrophage activation. ${ }^{14}$ This mechanism leads to the normal formation of other ocular structures. A failure of this vasculature to regress leads to the clinical spectrum of $\mathrm{PFV}^{2}$

A number of mechanisms have been proposed to influence the regression of vasculature with the help of genes and growth factors. Multiple recent animal studies reported the involvement of various signaling pathways in the pathogenesis of PFV, including protooncogene $s k i$, p53, tumor suppressor gene Arf, ephrin-B2, LRP5, ang-2, Bax and Bak, FZD4, and ephrin-A5. ${ }^{15-21}$ Abnormalities of neogenin receptor, a transmembrane receptor that is a part of normal neurogenesis, can cause the same pathologic findings found in PFV, such as elevated retrolental mass, unclosed retinal fissure in embryo, and microphthalmia. ${ }^{22}$ However, the role of these signaling pathways relative to PFV formation has not yet been defined.

\section{Clinical Presentations and Diagnosis of PFV}

PFV has various clinical spectrums depending on the location of the vasculature remnants that persist.
Anterior PFV can present with shallow anterior chamber, engorged iris vessels, retrolental membrane, cataract, and/or elongation of ciliary process. The membranous formation behind the lens can cause tractional force over the ciliary process resulting in decreased aqueous humor production and eventual ocular hypotony. In posterior PFV, the phenotype of hyaloidal stalk connecting between the optic nerve head and the back surface of the lens is the main clinical finding. ${ }^{2,23}$ The other manifestations include vitreous traction, epiretinal membrane, and optic nerve hypoplasia. Combined PFV comprises the clinical features of both anterior and posterior PFV. Tractional force from the entry of vitreous over the peripheral retina can cause retinal fold, retinal dysplasia, and retinal detachment (either tractional or rhegmatogenous type) in posterior and combined PFV. Microphthalmia can be found in any type of PFV, and it is associated with poor visual outcome even with appropriate treatment. ${ }^{23-25}$

Most PFV patients are unilateral, and less than $10 \%$ of cases have bilateral involvement. ${ }^{2,26}$ In bilateral cases, combined PFV is the major type found, and these patients tend to have more severe retinal involvement compared to unilateral cases. ${ }^{1,2}$ The syndrome of bilateral microcornea, posterior megalolenticonus, persistent fetal vasculature, and chorioretinal coloboma (MPPC syndrome) was reported in a group of patients. ${ }^{27-30}$ The PFV found in this syndrome were all bilateral cases with asymmetrical presentation between eyes.

Various systemic associations and syndromes have been reported, including (1) genetic disorders, such as Walker-Warburg syndrome, ${ }^{25}$ Dandy-Walker syndrome, trisomy 13, Norrie disease, Angelman syndrome, and incontinentia pigmenti; ${ }^{1,2}$ (2) perinatal infections, such as congenital cytomegalovirus infection and congenital rubella; ${ }^{25,31}$ (3) metabolic diseases, such as glucose 6-phosphate dehydrogenase deficiency; ${ }^{31}$ and, (4) maternal cocaine use during pregnancy. ${ }^{25}$

\section{Ocular Investigations for PFV}

More advanced instruments have been developed and introduced that have improved diagnosis of PFV, and that have enhanced our ability to predict the outcome of treatment, which facilitates better preoperative counselling to the family. These new investigations have yielded new ocular findings that we understand, and that improve diagnosis, treatment, and prognosis. 


\section{Hand-Held Fundus Photography and Intravenous Fluorescein Angiography}

Hand-held fundus photography can demonstrate the extent of the area of avascular retina, and it can be used as an adjunct investigation for more precise treatment and treatment planning. These photographs also benefit family counselling, and they have comparative benefit during follow-up. The anterior focus of handheld fundus photography can outline angle abnormalities, which can be useful for glaucoma risk assessment during long-term follow-up. Fluorescein angiography can accurately delineate the extent of avascular area, which might not be apparent on clinical examination or fundus photographs. The information obtained can be advantageous for laser photocoagulation under the guidance of angiography. In atypical cases, intravenous fluorescein angiography can be used to make the correct diagnosis. $^{32,33}$ For example, avascular retinal area detected by fluorescein angiography in the fellow eye indicates a diagnosis of familial exudative vitreoretinopathy. ${ }^{34}$

Furthermore, the use of intravenous fluorescein angiography can define the boundary of patent vessels within the vascular stalk in posterior or combined PFV. This evidence is beneficial for diagnosis and surgical planning with the aim of avoiding retinal trauma during the operation (Figure 1). Fluorescein angiography can also be used to assess the foveal anatomy, which is an important factor for postoperative visual prognosis. ${ }^{35}$

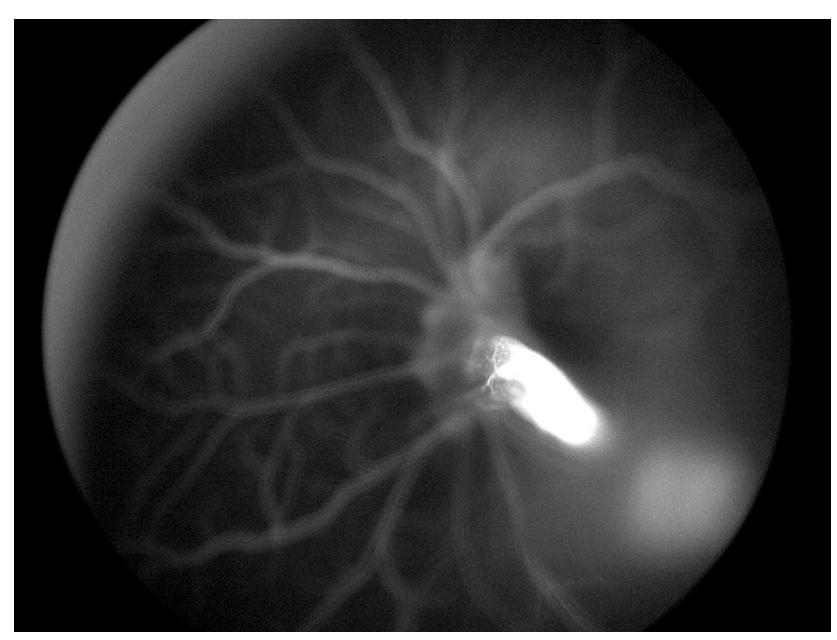

Figure I A photograph of intravenous fluorescein angiography of a posterior PFV patient showing the patency of the hyaloidal artery within the stalk.

\section{Ultra-Wide Field Photography and Ultra-Wide Field Fluorescein Angiography}

Ultra-wide field photography (UWFP) can capture the peripheral retina up to 200 degrees temporally and nasally without pupil dilation, which facilitates assessment for peripheral retina. This imaging technique is particularly useful in patients who can only be cooperative for a short time, such as children, because it consumes less time than conventional fundus photography. Although a diagnosis of PFV is not dependent on the peripheral retina, the benefit of peripheral retina assessment is for differential diagnosis in atypical cases. ${ }^{34}$ In addition, ultra-wide field fluorescein angiography (UWFA) can be taken with the use of oral fluorescein, which was reported to be a convenient method in pediatric patients. ${ }^{36,37}$

\section{Ultrasonography}

Ultrasonography is a crucial investigation for evaluating the posterior segment of eyes that have media opacity, such as cataract or retrolental membrane. The benefit of ultrasonography is not only assessing the extent of PFV pathology, but it can also be used to detect abnormal calcification or intraocular mass that would be obscured by the opacity. Importantly, the detection of intraocular calcification within a mass should heighten suspicion for retinoblastoma, and further investigations are needed to accurately determine the type of mass and its etiology. ${ }^{38,39}$ It should also be considered that ultrasonography is an operator-dependent procedure, so intra- and inter-operator variability occur. A very thin hyaloidal stalk can be missed in very small eyes and be discovered intraoperatively without appropriate preoperative preparation. ${ }^{40}$ Caution should be exercised before deciding whether the surgery should be performed by a pediatric cataract surgeon or a pediatric retina specialist. Concerning visual potential evaluation, A-scan ultrasonography can be used to measure axial length. If the axial length is less than $15 \mathrm{~mm}$ in PFV eyes or $3.5 \mathrm{~mm}$ or more disparity between eyes, the visual outcome is rarely better than light perception in the smaller eye even after surgical intervention. ${ }^{31}$

\section{Optical Coherence Tomography (OCT) and Handheld OCT}

OCT is capable of assessing microstructural changes in retinal layers that were found to be associated with visual prognosis. ${ }^{41}$ The reported characteristics of PFV from 


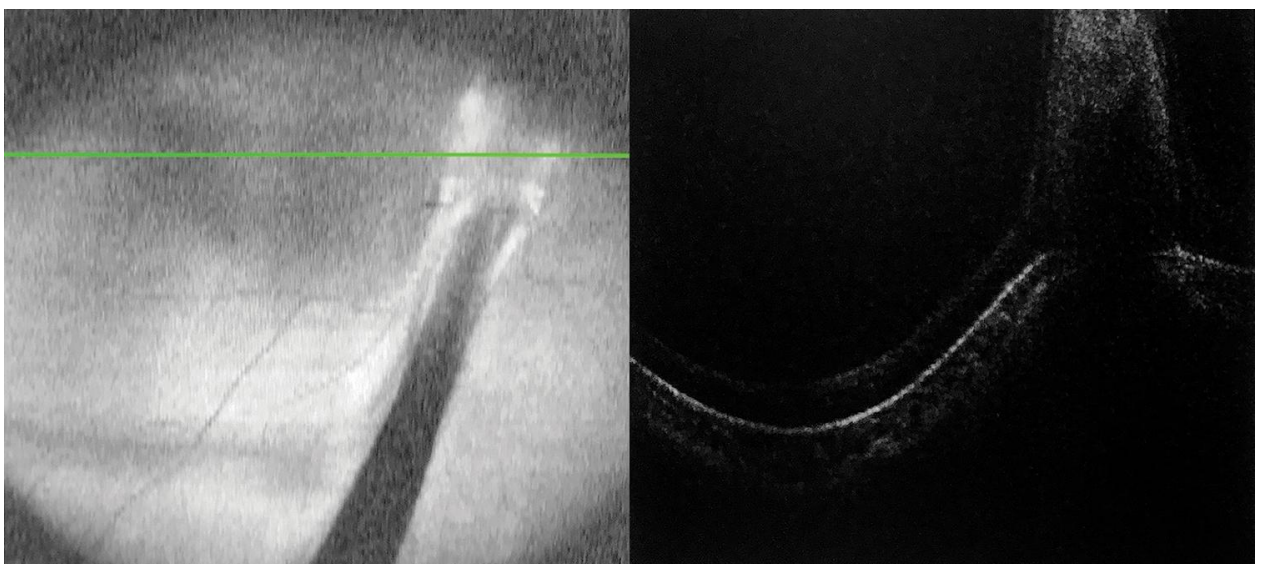

Figure 2 A handheld OCT image of a posterior PFV patient. (A) A scanning line on the center of macula in a PFV eye was demonstrated. (B) There was no foveal umbo identified within the entire macular area of this patient..

OCT included posterior hyaloidal organization, peripapillary vitreoretinal traction, loss of fovea umbo, foveal traction, and disruption of ellipsoid zone. ${ }^{42}$ Presence of posterior hyaloidal organization, loss of fovea umbo (Figure 2), or disruption of ellipsoid zone were factors reported to be significantly associated with poor vision in PFV patients. ${ }^{42}$ Handheld OCT is now commercially available, which facilitates examination of the macular anatomy in very young and non-cooperative children. The information derived from OCT is useful for planning and counselling of family members before advancing the patient to any interventions.

\section{Newer Investigations}

Optical Coherence Tomography Angiography (OCTA)

A noninvasive technology to detect intraluminal flow might be helpful for assessing the patency of persistent vessels, which is the primary pathology found in PFV. Vitreous hemorrhage was reported in a case of posterior PFV whose OCTA demonstrated blood flow in Bergmeister's papilla. ${ }^{43}$ OCTA may be useful in some patients for confirming the diagnosis and for further management. ${ }^{43}$

\section{Intraoperative Optical Coherence Tomography (Intraoperative OCT)}

Intraoperative OCT can be used to examine the integrity of the posterior lens surface or change in the retinal layers. This modality can investigate the structural change associated with the pathology in real-time, which facilitates intraoperative planning. For example, a PFV patient with attachment of the hyaloidal stalk to the posterior lens surface that is identified on intraoperative OCT might need lensectomy during the same procedure (Figure 3). Intraoperative OCT is also valuable for assessing the macular anatomy in the same manner as OCT, but it is performed during the intervention, which can make prediction of the postoperative visual outcome more precise. Moreover, overlying pathology appearing on the retinal surface, such as epiretinal membrane or vitreoretinal traction that requires membrane peeling, can be managed more confidently with the use of intraoperative OCT (Figure 4).

\section{PFV Management}

In cases with opacity obscuring the visual axis, surgery is usually indicated. In contrast, cases without media opacity or that have normal visual axis rarely require surgical intervention (Figure 5). The indication for intervention mainly depends on the pathological involvement in individual patients. Therefore, before deciding upon a treatment, complete ocular details must be obtained from all appropriate investigations. The goals of treatment in PFV include (1) vision improvement via mitigation of the visual axis disturbance; (2) reduction of associated complication, such as retinal detachment and glaucoma; (3) globe preservation in advanced cases; and, (4) good cosmetic appearance.

There is no definite indication for surgical intervention in PFV due to the clinical heterogeneity among PFV patients. An intervention might not be needed in a unilateral case without visual axis obscuration and 


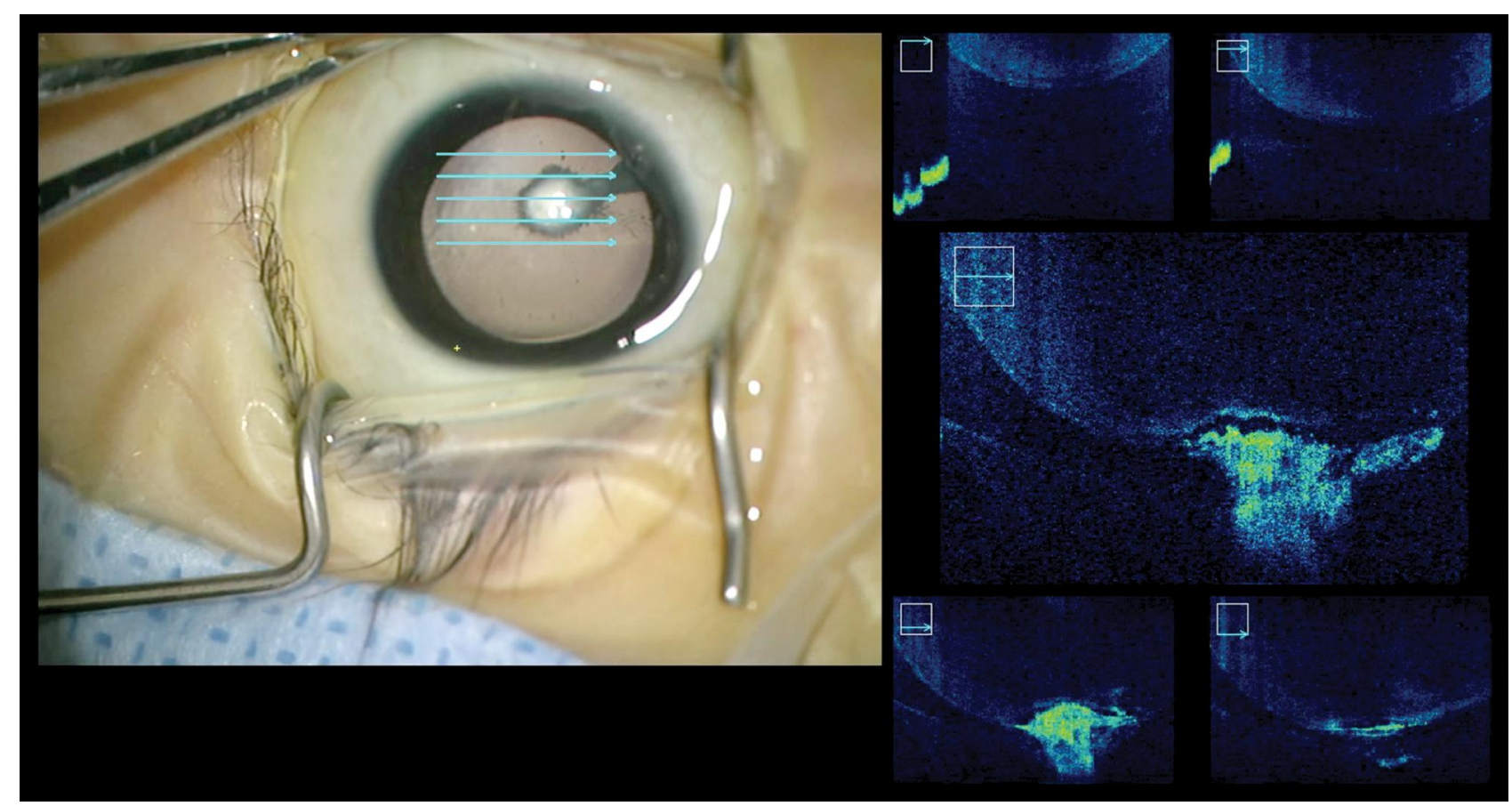

Figure 3 Intraoperative OCT images in a combined PFV patient. (A) the OCT image was focused on the posterior surface of the lens. (B) the adherence of the stalk to the posterior lens capsule was demonstrated.

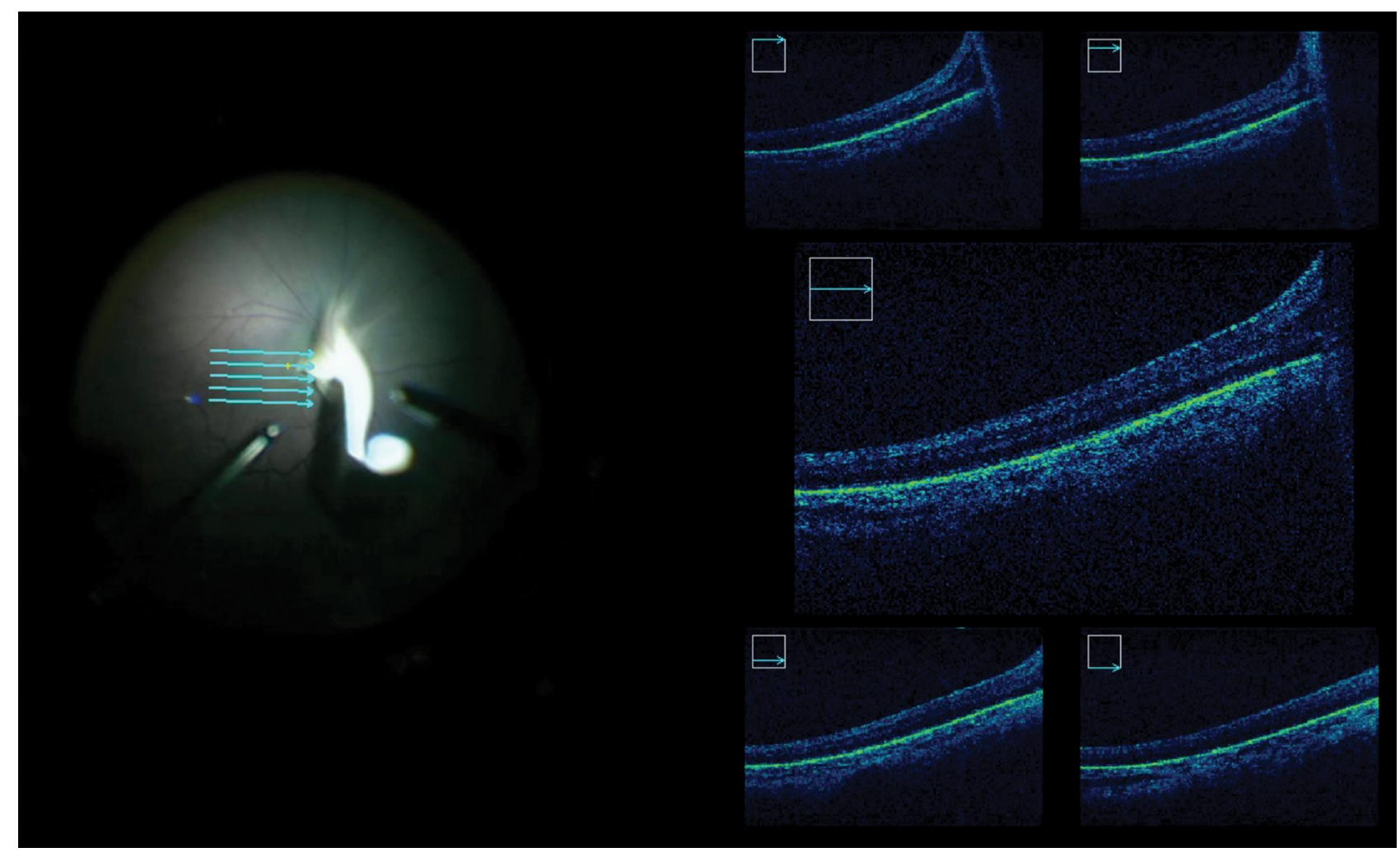

Figure 4 (A) A raster scan of the intraoperative OCT on the macula showing the preretinal and intraretinal structures in real-time. (B) The absence of normal foveal anatomy was demonstrated in this figure.

disease progression. Similarly, surgery might not be a good option in cases with advanced pathology, such as severe optic nerve hypoplasia, severe retinal detachment, or microphthalmia, because postoperative vision is often poor in these cases. ${ }^{25}$ Surgical intervention on these eyes might increase the risk of postoperative complications. 


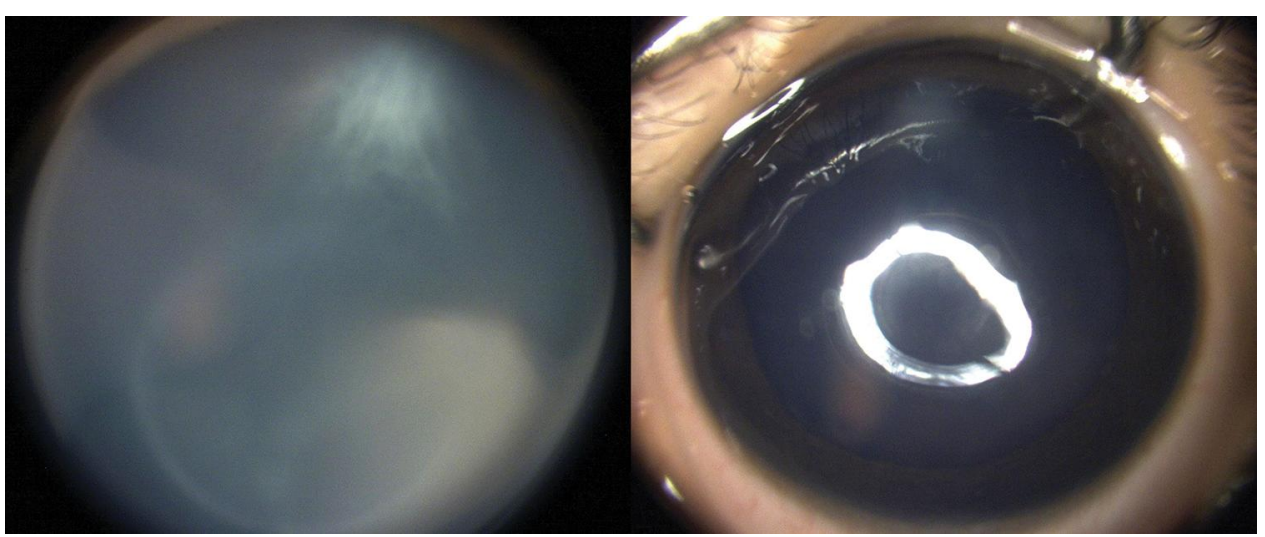

Figure 5 Anterior segment photographs of a 4-year-old boy with (A) mild eccentric cataract and (B) without visual axis involvement. Generally, surgical intervention is not indicated in such cases.

The common indications for surgical intervention include significant media opacities from cataract or retrolental membrane, progressive shallowing of that anterior chamber caused by cataract, uncontrolled glaucoma or secondary ocular hypotony from ciliary process pulling, vitreous hemorrhage, and retinal detachment following vitreoretinal traction. $^{2,44}$

If surgery is indicated, the sooner the surgery is performed, the better the outcome will be for the patient. ${ }^{25,45}$ Delay in surgical treatment will increase the risk of PFVrelated complications and postoperative deprivational amblyopia. $^{46}$ Moreover, surgical delay will lead to no improvement in retinal fold, vitreomacular traction, and tractional retinal detachment if glial cells and the fibrovascular remnant are left to mature before intraocular operations are performed. ${ }^{47,48}$ Improvement in retinal fold was reported in children who were operated upon prior to the age of 13 months. ${ }^{48}$ Finally, the earlier that surgery is performed, the earlier that visual rehabilitation can start.

\section{Surgical Management}

Once the patient is under general anesthesia, a comprehensive ocular examination should be repeated to obtain up-to-themoment information. Ocular investigations, such as ocular ultrasonography or fluorescein angiography, can be repeated to comprehensively identify abnormalities within the eye(s), and can be used to determine the most appropriate surgical technique.

The two main surgical incision alternatives that can be performed are the limbal and pars plicata incisions depending on ocular pathology and surgeon preference. The limbal incision has the benefit of avoiding interruption of the vitreous base and the centrally pulled peripheral retina. $^{25,49}$ Therefore, the risk of iatrogenic complications to the peripheral retina can be minimized. In cases with maldevelopment of the pars plana, especially in microphthalmic eyes, the limbal incision is generally preferred. The pars plicata or posterior approach is similar to conventional sclerotomies used in adults, but with different distance for placing sclerotomies. This technique can facilitate early excision of the hyaloidal stalk; thus, reducing manipulation of the pulled retina at the back and decreasing the risk of retinal breaks. ${ }^{40}$ Furthermore, the anterior chamber and sometimes the crystalline lens are left untouched, which permits better visualization during vitrectomy. Posterior approach is superior to limbal incision in cases where the lens can be preserved (ie, lenssparing vitrectomy). ${ }^{50}$ The location of sclerotomy varies from 0.5 to $2 \mathrm{~mm}$ from the limbus depending on patient age and severity of microphthalmia. Age-based sclerotomy placement can be used as a guide for placing safe sclerotomies. ${ }^{51}$ However, that guideline was developed from anatomically normal eyes, which could be different from PFV eyes.

In our experience, a limbal approach is preferred by making the incision using trocars through the limbus (Figure 6A). Viscoelastic is then injected to deepen and stabilize the anterior chamber. The lens is then removed via aspiration within the capsular bag to avoid unnecessary traction on the vitreous base. Next, the posterior capsule is cut circularly around the location where the hyaloidal stalk is inserted. After release of the stalk, a complete vitrectomy is then performed so it falls back independently (Figure 6B). It is crucial to note the presence of retinal tissue within the stalk, so that unnecessary damage can be avoided that could lead to rhegmatogenous retinal 


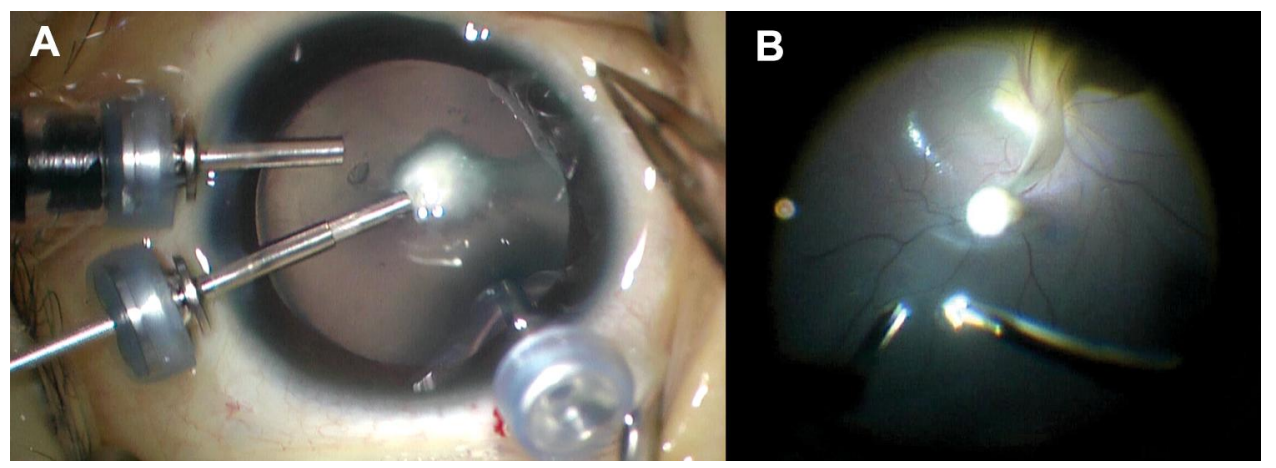

Figure 6 (A) Intraoperative view of a limbal approach vitrectomy in a combined PFV eye. (B) the stalk was excised from its anterior attachment at the lens capsule.

detachment. An air-fluid exchange is performed to move the stalk away from the macula. Then, the patient should be positioned accordingly. Intraocular lens implantation in these PFV cases is not recommended at the time of surgery. Surgeons can leave the anterior capsule for placement of an intraocular lens in the future in eyes with some visual potential. We usually inject sub-tenon's steroid and subconjunctival antibiotics at the end of the procedure. Topical antibiotic eye drops, topical steroid eye drops, and cycloplegics are prescribed postoperatively.

Intraocular lens implantation may be employed later in the sulcus by leaving the anterior capsule when doing lensectomy during the first surgery. However, leaving the anterior capsule could lead to a higher likelihood of posterior synechiae. Therefore, in such cases, cycloplegic eye drops need to be instilled properly. The rate of reoperation and visual axis opacification in these patients following surgery was as high as $60 \%$ if the vitreous and retrolental membranes were not completely removed. ${ }^{52,53}$ Therefore, the vitreous and retrolental membranes need to be completely excised in these cases, especially in cases with ciliary body elongation if the anterior capsule is planned to be left for future intraocular lens implantation.

\section{Special Advancements in PFV Surgery Intraoperative Optical Coherence Tomography (Intraoperative OCT)}

The use of intraoperative OCT provides real-time benefit during the surgical procedure. In anterior and combined PFV, it can be used to evaluate posterior capsule integrity, which will help to determine whether sacrifice of the lens is required or not. It also helps to assess the macular anatomy during surgery for the presence of the preretinal membrane or vitreomacular traction, both of which require peeling. Intraoperative OCT can also be used to evaluate visual potential by assessing for the presence of normal foveal anatomy.

\section{Special Vitrectomy Platforms}

Short instruments and smaller gauge vitrectomy are ideal platforms for use in pediatric eyes since the vitreous volume is small, the anteroposterior thickness of the lens is larger, and the axial length of the eye is shorter compared to adult eyes. ${ }^{54}$ Shorter instruments can reduce the risk of unwanted complications. Short 25-gauge vitrectomy, which is approximately two-thirds the length of adult instruments, is now commercially available for easier manipulation in the limited space of pediatric eyes. ${ }^{55}$ A smaller 27-gauge vitrectomy platform has been successfully used in adult eyes. The use of this sized platform can produce stable self-sealing sclerotomy wounds, which reduced the risk of postoperative hypotony and endophthalmitis. ${ }^{56}$ However, the flexibility of these smaller surgical instruments and the reduced flow rate are of concern when used in pediatric eyes, especially when the membrane is thick and firmly adhered. ${ }^{57}$

\section{Endoscopic Vitrectomy}

Endoscopic vitrectomy has been proven effective in selected cases of adult vitreoretinal surgery. This technique provides a side-on view that is different from the above view produced by conventional vitrectomy. However, endoscopic vitrectomy requires additional skills and experience before surgeons can perform it with confidence. The smaller space of pediatric eyes and the complexity of pediatric retinal diseases are two factors that needed to be considered prior to selecting it for the operation. In PFV, the side-on view can evaluate for the presence of retinal tissue pulled by the hyaloidal stalk while avoiding serious complications, such as bleeding and cutting the retina. ${ }^{58}$ Endoscopic vitrectomy has been used 
successfully in complex cases, including microcornea, posterior megalolenticonus, PFVS, and coloboma syndrome. ${ }^{59}$ Endoscopic vitrectomy is currently only available in 20-gauge and 23-gauge platforms.

\section{Anti-Vascular Endothelial Growth Factor (Anti-VEGF)}

Anti-VEGF has been successfully used in many pediatric retinal diseases, such as retinopathy of prematurity, ${ }^{60,61}$ familial exudative vitreoretinopathy, ${ }^{62}$ and Coats disease $^{63}$ with evidence of increased level of VEGF in the treated eyes. Concerning its use in PFV, it was reported that VEGF and placental growth factor both played a modulatory role in hyaloid regression in mice. ${ }^{64}$ At our center, anti-VEGF has been injected at the end of the surgery to reduce the risk of intraocular bleeding and postoperative inflammation. Studies that have investigated the role and efficacy of anti-VEGF in PFV remain scarce, and more studies are needed.

\section{Nonsurgical Management of PFV}

Nonsurgical management can be adopted in selected cases, such as non-progressive cases and cases with non-central opacity that does not cause any visual deficit. Furthermore, in severe cases with very poor visual prognosis, such as cases with optic nerve hypoplasia, retinal dysplasia, or combined anomalies of the eyes, surgery may be of little help for improving vision. These cases may, therefore, be considered for management by nonsurgical methods. However, if a nonsurgical option is indicated, careful follow-up in the near-term should be performed to early detect possible complications, such as progressive cataract and glaucoma. The incidence of progression of disease to complete blindness in cases without surgery ranges from $27 \%$ to $70 \%$. $^{31,45,49,65}$ Approximately $30 \%$ of cases were reported to remain at least light perception. ${ }^{49}$ The smallest level of vision is still valuable for these patients, especially in cases with bilateral involvement, since it allows patients to maintain a normal sleep-wake cycle. ${ }^{66}$ In absolutely blinded eyes, an ocularist should be consulted for ocular prostheses to promote normal orbital growth, which will result in better cosmetic outcome when the patient grows up.

A multidisciplinary team that includes pediatric ophthalmologists and optometrists should be consulted to correct refractive errors and treat anisometropic amblyopia. Polycarbonate glasses should be worn to protect the remaining eye from accidental trauma. Parents and patients should be advised to return to the clinic as soon as possible when abnormal visual symptoms occur.

\section{PFV Complications and Management}

Even though surgical treatment yields a number of benefits, it is also associated with a number of risks in this patient population. The two main postoperative complications found in PFV are retinal detachment and secondary glaucoma. If a retinal tear occurs during surgery, it usually leads to treatment failure from rhegmatogenous retinal detachment. This complication must, therefore, be prevented via a complete preoperative ocular evaluation as well as delicate execution of each step of surgery, including careful placement of sclerotomy or using limbal incision in cases with poorly developed pars plana area or severe microphthalmia.

Secondary glaucoma is a lifelong complication found in PFV for which the causative mechanisms are closed angle, neovascular, or mixed. Approximately $10 \%$ to $30 \%$ of postoperative patients develop this complication depending on various factors, such as coexisting pathology, younger age at surgery, microcornea, and aphakic status. ${ }^{31,45,48}$ Therefore, lifetime follow-up should be practiced in these patients in order to start early treatment when indicated.

\section{Visual Outcomes}

Factors associating with visual outcomes include the type of PFV, age at presentation, bilaterality, associated anomalies, and secondary complications, such as glaucoma. 2,25,31,45,49,67 Anterior type PFV is prognostically associated with better vision compared to combined or posterior type. ${ }^{68}$ Moreover, younger age at presentation was reported to correlate with better vision after treatment. ${ }^{69}$ Cases with axial length less than $15 \mathrm{~mm}$ or $3.5 \mathrm{~mm}$ disparity between eyes were observed to have poorer outcome. ${ }^{31}$ However, patients who underwent surgical intervention developed form vision, counting fingers, and fix and follow or better for at least 6 months after surgery. ${ }^{31}$ Unfortunately, approximately $10 \%$ of patients progressed to phthisis bulbi even after being surgically treated. ${ }^{49}$

\section{Conclusion}

PFV is a congenital condition that needs to be detected early in life. Early detection leads to early comprehensive 
evaluation and treatment that will improve patient outcomes. Innovative improvements, especially in investigative instruments and surgical procedures, have not only contributed new knowledge about the disease, but they have also improved both functional outcome and quality of life of PFV patients.

\section{Disclosure}

All authors declare no conflicts of interest, and no financial support from the companies that produce and/or distribute the drugs, devices, or materials described in this report.

\section{References}

1. Reese AB. Persistent hyperplastic primary vitreous*: the Jackson Memorial Lecture. Am J Ophthalmol. 1955;40(3):326a. doi:10.10 16/0002-9394(55)91866-3

2. Goldberg MF. Persistent fetal vasculature (PFV): an integrated interpretation of signs and symptoms associated with persistent hyperplastic primary vitreous (PHPV) LIV Edward Jackson Memorial Lecture. Am J Ophthalmol. 1997;124(5):587-626. doi:10.1016/S000 2-9394(14)70899-2

3. Ghiasvand NM, Shirzad E, Naghavi M, Mahdavi MR. High incidence of autosomal recessive nonsyndromal congenital retinal nonattachment (NCRNA) in an Iranian founding population. Am J Med Genet. 1998;78(3):226-232. doi:10.1002/(SICI)1096-8628(1998070 7) 78:3<226::AID-AJMG3>3.0.CO;2-N

4. Khan K, Logan CV, McKibbin M, et al. Next generation sequencing identifies mutations in Atonal homolog 7 (ATOH7) in families with global eye developmental defects. Hum Mol Genet. 2012;21(4):7 76-783. doi:10.1093/hmg/ddr509

5. Galal AH, Kotoury AI, Azzab AA. Bilateral persistent hyperplastic primary vitreous: an Egyptian family supporting a rare autosomal dominant inheritance. Genet Counsel. 2006;17(4):441.

6. Dhingra S, Shears DJ, Blake V, Stewart H, Patel CK. Advanced bilateral persistent fetal vasculature associated with a novel mutation in the Norrie gene. Br J Ophthalmol. 2006;90(10):1324-1325. doi:10. 1136/bjo.2005.088625

7. Pendergast SD, Trese MT, Liu X, Shastry BS. Study of the Norrie disease gene in 2 patients with bilateral persistent hyperplastic primary vitreous. Arch Ophthalmol. 1998;116(3):381-382.

8. Payabvash S, Anderson JS, Nascene DR. Bilateral persistent fetal vasculature due to a mutation in the Norrie disease protein gene. Neuroradiol J. 2015;28(6):623-627. doi:10.1177/1971400915609350

9. Hasbrook M, Yonekawa Y, Van Laere L, Shah AR, Capone A. Bilateral persistent fetal vasculature and a chromosome 10 mutation including COX15. Can J Ophthalmol. 2017;52(6):e203-5. doi:10.10 16/j.jcjo.2017.04.019

10. Weiner GA, Nudleman E. Microcornea, posterior megalolenticonus, persistent fetal vasculature, and coloboma syndrome associated with a new mutation in ZNF408. Ophthalmic Surg Lasers Imaging Retina. 2019;50(4):253-256. doi:10.3928/23258160-20190401-10

11. Robitaille JM, Wallace K, Zheng B, et al. Phenotypic overlap of familial exudative vitreoretinopathy (FEVR) with persistent fetal vasculature (PFV) caused by FZD4 mutations in two distinct pedigrees. Ophthalmic Genet. 2009;30(1):23-30. doi:10.1080/138168 10802464312

12. Patau K. Multiple congenital anomaly caused by an extra autosome. Lancet. 1960;790-793. doi:10.1016/S0140-6736(60)90676-0

13. Mutlu F, Leopold IH. The structure of fetal hyaloid system and tunica vasculosa lentis. Arch Ophthalmol. 1964;71(1):102-110. doi:10.10 01/archopht.1964.00970010118019
14. Ito M, Yoshioka M. Regression of the hyaloid vessels and pupillary membrane of the mouse. Anat Embryol (Berl). 1999;200(4):403-411. doi: $10.1007 / \mathrm{s} 004290050289$

15. McGannon P, Miyazaki Y, Gupta PC, Traboulsi EI, Colmenares C. Ocular abnormalities in mice lacking the Ski proto-oncogene. Invest Ophthalmol Vis Sci. 2006;47(10):4231-4237. doi:10.1167/iovs.051543

16. Freeman-Anderson NE, Zheng Y, McCalla-Martin AC, et al. Expression of the Arf tumor suppressor gene is controlled by Tgf $\beta 2$ during development. Development. 2009;136(12):2081-2089. doi:10. $1242 /$ dev. 033548

17. McKeller RN, Fowler JL, Cunningham JJ, et al. The Arf tumor suppressor gene promotes hyaloid vascular regression during mouse eye development. Proc Natl Acad Sci. 2002;99(6):3848-3853. doi:10. 1073/pnas.052484199

18. Reichel MB, Ali RR, D’Esposito F, et al. High frequency of persistent hyperplastic primary vitreous and cataracts in $\mathrm{p} 53$-deficient mice. Cell Death Differ. 1998;5(2):156-162.

19. Hackett SF, Wiegand S, Yancopoulos G, Campochiaro PA. Angiopoietin-2 plays an important role in retinal angiogenesis. J Cell Physiol. 2002;192(2):182-187. doi:10.1002/jcp.10128

20. Hahn P, Lindsten T, Tolentino M, et al. Persistent fetal ocular vasculature in mice deficient in bax and bak. Arch Ophthalmol. 2005;123 (6):797-802. doi:10.1001/archopht.123.6.797

21. Salvucci O, Ohnuki H, Maric D, et al. EphrinB2 controls vessel pruning through STAT1-JNK3 signalling. Nat Commun. 2015;6 (1):1-7. doi:10.1038/ncomms 7576

22. Lin S, Liu W, Chen CL, et al. Neogenin-loss in neural crest cells results in persistent hyperplastic primary vitreous formation. $J \mathrm{Mol}$ Cell Biol. 2020;12(1):17-31.

23. Tartarella MB, Takahagi RU, Braga AP, Fortes Filho JB. Persistent fetal vasculature: ocular features, management of cataract and outcomes. Arq Bras Oftalmol. 2013;76(3):185-188. doi:10.1590/ S0004-27492013000300011

24. Karacorlu M, Hocaoglu M, Muslubas IS, Arf S, Ersoz MG, Uysal O. Functional and anatomical outcomes following surgical management of persistent fetal vasculature: a single-center experience of 44 cases. Graefes Arch Clin Exp Ophthalmol. 2018;256(3):495-501. doi:10.10 07/s00417-017-3886-4

25. Dass AB, Trese MT. Surgical results of persistent hyperplastic primary vitreous. Ophthalmology. 1999;106(2):280-284. doi:10.1016/ S0161-6420(99)90066-0

26. Pollard ZF. Persistent hyperplastic primary vitreous: diagnosis, treatment and results. Trans Am Ophthalmol Soc. 1997;95:487.

27. Ranchod TM, Quiram PA, Hathaway N, Ho LY, Glasgow BJ, Trese MT. Microcornea, posterior megalolenticonus, persistent fetal vasculature, and coloboma: a new syndrome. Ophthalmology. 2010;117(9):1843-1847. doi:10.1016/j.ophtha.2009.12.045

28. Takkar B, Chandra P, Kumar V, Agrawal R. A case of iridofundal coloboma with persistent fetal vasculature and lens subluxation. $J \mathrm{Am}$ Assoc Pediatr Ophthalmol Strabismus. 2016;20(2):180-182. doi:10. 1016/j.jaapos.2015.12.004

29. Lee JS, Lee JE, Shin YG, Choi HY, Oum BS, Kim HJ. Five cases of microphthalmia with other ocular malformations. Korean J Ophthalmol. 2001;15(1):41-47. doi:10.3341/kjo.2001.15.1.41

30. Seitz BE, Naumann GO. Bilateral congenital dentiform cataract and extreme microcornea in eyes with uveal colobomas and persistent hyperplastic primary vitreous. $B r J$ Ophthalmol. 1996;80(4):378. doi:10.1136/bjo.80.4.378-a

31. Sisk RA, Berrocal AM, Feuer WJ, Murray TG. Visual and anatomic outcomes with or without surgery in persistent fetal vasculature. Ophthalmology. 2010;117(11):2178-2183. doi:10.1016/j.ophtha.20 10.03.062

32. Cernichiaro-Espinosa LA, Tran KD, Berrocal AM. Imaging modalities in pediatric vitreoretinal disorders. Curr Ophthalmol Rep. 2018;6(1):17-23. doi:10.1007/s40135-018-0159-2 
33. Jeng-Miller KW, Joseph A, Baumal CR. Fluorescein angiography in persistent fetal vasculature. Ophthalmology. 2017;124(4):455. doi:10. 1016/j.ophtha.2016.09.033

34. Kartchner JZ, Hartnett ME. Familial exudative vitreoretinopathy presentation as persistent fetal vasculature. Am J Ophthalmol Case Rep. 2017;6:15-17. doi:10.1016/j.ajoc.2017.01.001

35. Rothfield LD, Cernichiaro-Espinosa LA, Alabiad CR, et al. Microcornea, posterior megalolenticonus, persistent fetal vasculature, chorioretinal coloboma (MPPC) syndrome: case series post vitrectomy. Am J Ophthalmol Case Rep. 2019;14:5-9. doi:10.1016/ j.ajoc.2019.01.005

36. Ali SM, Khan I, Khurram D, Kozak I. Ultra-widefield angiography with oral fluorescein in pediatric patients with retinal disease. JAMA Ophthalmol. 2018;136(5):593-594. doi:10.1001/jamaophthalmol.20 18.0462

37. Sugimoto M, Matsubara H, Miyata R, Matsui Y, Ichio A, Kondo M. UltraWideField fluorescein angiography by oral administration of fluorescein. Acta Ophthalmol. 2014;92(5):e417-8. doi:10.1111/aos.12323

38. Shields CL, Schoenberg E, Kocher K, Shukla SY, Kaliki S, Shields JA. Lesions simulating retinoblastoma (pseudoretinoblastoma) in 604 cases: results based on age at presentation. Ophthalmology. 2013;120 (2):311-316. doi:10.1016/j.ophtha.2012.07.067

39. Francis JH, Marr BP, Abramson DH. Classification of vitreous seeds in retinoblastoma: correlations with patient, tumor, and treatment characteristics. Ophthalmology. 2016;123(7):1601-1605. doi:10.101 6/j.ophtha.2016.02.036

40. Mittra RA, Huynh LT, Ruttum MS, et al. Visual outcomes following lensectomy and vitrectomy for combined anterior and posterior persistent hyperplastic primary vitreous. Arch Ophthalmol. 1998;116 (9):1190-1194. doi:10.1001/archopht.116.9.1190

41. Kimura D, Fukumoto M, Sato T, et al. Optical coherence tomography findings of falciform retinal detachment complicated with persistent fetal vasculature. BMC Ophthalmol. 2018;18(1):216. doi:10.1186/ s12886-018-0893-0

42. De la Huerta I, Mesi O, Murphy B, Drenser KA, Capone A, Trese MT. Spectral domain optical coherence tomography imaging of the macula and vitreomacular interface in persistent fetal vasculature syndrome with posterior involvement. Retina. 2019;39 (3):581-586. doi:10.1097/IAE.0000000000001993

43. Jeon H, Kim J, Kwon S. OCT angiography of persistent hyaloid artery: a case report. BMC Ophthalmol. 2019;19(1):141. doi:10.11 86/s12886-019-1155-5

44. Smith RE. Persistent hyperplastic primary vitreous: results of surgery. Trans Am Acad Ophthalmol Otolaryngol. 1974;78:911-925.

45. Hunt A, Rowe N, Lam A, Martin F. Outcomes in persistent hyperplastic primary vitreous. $\mathrm{Br} J$ Ophthalmol. 2005;89(7):859-863. doi:10.1136/bjo.2004.053595

46. Cheng LS, Kuo HK, Lin SA, Kuo ML. Surgical results of persistent fetal vasculature. Chang Gung Med J. 2004;27(8):602-608.

47. Manschot WA. Persistent hyperplastic primary vitreous: special reference to preretinal glial tissue as a pathological characteristic and to the development of the primary vitreous. AMA Arch Ophthalmol. 1958;59(2):188-203. doi:10.1001/archopht.1958.0094 0030054004

48. Bosjolie A, Ferrone P. Visual outcome in early vitrectomy for posterior persistent fetal vasculature associated with traction retinal detachment. Retina. 2015;35(3):570-576. doi:10.1097/IAE.0000000 000000353

49. Walsh MK, Drenser KA, Capone A, Trese MT. Early vitrectomy effective for bilateral combined anterior and posterior persistent fetal vasculature syndrome. Retina. 2010;30(4):S2-8. doi:10.1097/ IAE.0b013e3181d34a9e

50. Shaikh S, Trese MT. Lens-sparing vitrectomy in predominately posterior persistent fetal vasculature syndrome in eyes with nonaxial lens opacification. Retina. 2003;23(3):330-334. doi:10.1097/00006982200306000-00007
51. Lemley CA, Han DP. An age-based method for planning sclerotomy placement during pediatric vitrectomy: a 12-year experience. Trans Am Ophthalmol Soc. 2007;105:86.

52. Warren N, Trivedi RH, Wilson ME. Persistent fetal vasculature with elongated ciliary processes in children. Am $J$ Ophthalmol. 2019;198:25-29. doi:10.1016/j.ajo.2018.09.019

53. Liu JH, Li SF, Deng GD, Jiao YH, Lu H. Outcomes of secondary sulcus intraocular lens implantation in unilateral anterior persistent fetal vasculature. Int J Ophthalmol. 2019;12(4):592.

54. Ozdemir O, Tunay ZO, Acar DE, Erol MK, Sener E, Acar U. The relationship of birth weight, gestational age, and postmenstrual age with ocular biometry parameters in premature infants. Arq Bras Oftalmol. 2015;78(3):146-149. doi:10.5935/0004-2749.20150038

55. Leung EH, Berrocal AM. Pediatric microincision vitreoretinal surgery. Int Ophthalmol Clin. 2016;56(4):203-208. doi:10.1097/ IIO.0000000000000143

56. Osawa S, Oshima Y. 27-Gauge vitrectomy. In: Microincision Vitrectomy Surgery. Vol. 54. Karger Publishers; 2014:54-62.

57. Abulon DJ, Buboltz DC. Porcine vitreous flow behavior during high-speed vitrectomy up to 7500 cuts per minute. Transl Vis Sci Technol. 2016;5(1):7. doi:10.1167/tvst.5.1.7

58. Hubbard GI, Engelbrecht N, Wong S, Lee T. Endoscopic vitrectomy in children. Retina Times. 2012;30:18-20.

59. Bowe T, Rahmani S, Yonekawa Y. Endoscopic vitrectomy for microcornea, posterior megalolenticonus, persistent fetal vasculature, coloboma syndrome. Ophthalmology. 2017;124(12):1742. doi:10.1016/j. ophtha.2017.07.028

60. Stahl A, Lepore D, Fielder A, et al. Ranibizumab versus laser therapy for the treatment of very low birthweight infants with retinopathy of prematurity (RAINBOW): an open-label randomised controlled trial. Lancet. 2019;394(10208):1551-1559. doi:10.1016/S0140-6736(19) 31344-3

61. Lien R, Yu MH, Hsu KH, et al. Neurodevelopmental outcomes in infants with retinopathy of prematurity and bevacizumab treatment. PLoS One. 2016;11(1):e0148019. doi:10.1371/journal.pone.0148019

62. Quiram PA, Drenser KA, Lai MM, Antonio Capone JR, Trese MT. Treatment of vascularly active familial exudative vitreoretinopathy with pegaptanib sodium (Macugen). Retina. 2008;28(3):S8-12. doi:10.1097/IAE.0b013e3181679bf6

63. Sun Y, Jain A, Moshfeghi DM. Elevated vascular endothelial growth factor levels in Coats disease: rapid response to pegaptanib sodium. Graefes Arch Clin Exp Ophthalmol. 2007;245(9):1387-1388. doi:10.1007/s00417-007-0559-8

64. Feeney SA, Simpson DA, Gardiner TA, Boyle C, Jamison P, Stitt AW. Role of vascular endothelial growth factor and placental growth factors during retinal vascular development and hyaloid regression. Invest Ophthalmol Vis Sci. 2003;44(2):839-847. doi:10.11 67/iovs.02-0040

65. Anteby I, Cohen E, Karshai I, BenEzra D. Unilateral persistent hyperplastic primary vitreous: course and outcome. J Am Assoc Pediatr Ophthalmol Strabismus. 2002;6(2):92-99. doi:10.1067/mpa. 2002.121324

66. Davitt BV, Morgan C, Cruz OA. Sleep disorders in children with congenital anophthalmia and microphthalmia. J Am Assoc Pediatr Ophthalmol Strabismus. 1997;1(3):151-153. doi:10.1016/S1091-85 31(97)90057-4

67. Karr DJ, Scott WE. Visual acuity results following treatment of persistent hyperplastic primary vitreous. Arch Ophthalmol. 1986;104:662-667. doi:10.1001/archopht.1986.01050170052020

68. Frezzotti R, Bardelli AM, Morocutti A, Pannini S. The pars plana approach in two cases of persistent hyperplastic primary vitreous (PHPV). Ophthalmic Paediatr Genet. 1984;4(2):107-110. doi:10.31 09/13816818409007845

69. Pollard ZF. Results of treatment of persistent hyperplastic primary vitreous. Ophthalmic Surg. 1991;22:48-52. 


\section{Publish your work in this journal}

Clinical Ophthalmology is an international, peer-reviewed journal covering all subspecialties within ophthalmology. Key topics include: Optometry; Visual science; Pharmacology and drug therapy in eye diseases; Basic Sciences; Primary and Secondary eye care; Patient Safety and Quality of Care Improvements. This journal is indexed on PubMed

Submit your manuscript here: https://www.dovepress.com/clinical-ophthalmology-journal
Central and CAS, and is the official journal of The Society of Clinical Ophthalmology (SCO). The manuscript management system is completely online and includes a very quick and fair peer-review system, which is all easy to use. Visit http://www.dovepress.com/ testimonials.php to read real quotes from published authors. 